\title{
INSERÇão E EXTRAÇão DE MARCa D’ÁGUA EM IMAGENS DigitaIS No DOMÍNIO WAVELET
}

\author{
JAQUELINE F. SILVA ${ }^{1}$, MARCO APARECIDO Q. DUARTE ${ }^{2}$, FRANCISCO VILLARREAL ALVARADO ${ }^{3}$
}

\section{Laboratório de Sistemas Inteligentes, Departamento de Engenharia Elétrica, Universidade Estadual Paulista - UNESP Caixa postal 56, 13385-000, ILHA SOLTEIRA, SP-BRASIL}

\section{Universidade Estadual de Mato Grosso do Sul - UEMS - Curso de Matemática} 79540-000, Cassilândia, MS - Brasil

\section{Departamento de Matemática, Universidade Estadual Paulista - UNESP Caixa postal 56, 13385-000, Ilha Solteira, SP - Brasil}

\author{
E-mails:jaquelineferreira21@hotmail.com, marco@uems.br, \\ villa@mat.feis.unesp.br
}

\begin{abstract}
This paper presents a new proposal for the insertion and extraction of watermark into digital images based on the wavelet transform. The insertion of the watermark is perfomed in a high frequency sub-band, containing the horizontal detail coefficients of the host image, decomposed once by the twodimensional discrete wavelet transform. This sub-band is once more decomposed before inserting the watermark. The encryption process includes the division of the watermark in blocks, an encoding algorithm, exchanging positions of elements and random allocation of the blocks at the time of its inclusion in the sub-band chosen. The robustness of the method is verified by applying three very common attacks in images with watermarks, noise addition, lossy compression and JPEG compression.
\end{abstract}

Keywords- Wavelet Transform, Watermarking, Digital Image Processing.

Resumo- Este artigo apresenta uma proposta de inserção e extração de marca d'água em imagens digitais baseada na transformada wavelet. A inserção da marca d'água é feita na sub-banda de alta frequência que contém os coeficientes de detalhes horizontais da imagem hospedeira obtida após ser decomposta pela transformada wavelet discreta bidimensional no primeiro nível de decomposição. Tal subbanda é novamente decomposta antes da inserção da marca d'água. O processo criptográfico inclui a divisão da marca d'água em blocos, um algoritmo de codificação, troca de posições de elementos e alocação aleatória dos blocos no momento de sua inserção na sub-banda escolhida. A robustez do método é verificada com aplicação de três tipos de ataques muito frequentes em imagens com marcas d'água, sendo estes a adição de ruído, a compressão com perdas e a compressão JPEG.

Palavras-chave- Transformada Wavelet, Marca d'água, Processamento Digital de Imagens.

\section{Introdução}

O processamento de imagens é uma área de estudo muito importante na atualidade, pois, com o advento da internet, diariamente milhões imagens são transmitidas, armazenadas, analisadas, codificadas e compactadas (Wysocki et al., 2005). Com objetivos como os listados anteriormente, vários métodos têm sido propostos, usando as mais variadas ferramentas de auxílio ao processamento de imagens (Silva et al, 2007; Silva, 2008; Stollnitz et al., 1996; Wysocki et al., 2005). A transformada wavelet é uma das ferramentas que se destacam nesta área devido as suas propriedades de multirresolução e a fácil implementação computacional dos seus algoritmos de decomposição e reconstrução (Daubechies, 1992; Silva et al., 2007; Silva, 2008; Stollnitz et al., 1996).
O processamento de imagens é usado na internet, na televisão, na medicina, na previsão do tempo, em geoprocessamento, na área de segurança, entre outras. Por isso existe a necessidade constante da proposição de métodos inovadores que possam propiciar o tratamento eficiente e seguro das imagens envolvidas em cada processo. Esse tratamento pode ser compressão, eliminação de ruído, detecção de singularidades, codificação e decodificação, entre outros (Stollnitz et al., 1996). Uma alternativa para oferecer segurança e autonomia aos documentos digitais é o uso de assinaturas digitais. Esse tipo de assinatura é caracterizado como marca d'água digital. $\mathrm{O}$ uso de marca d'água digital pode dificultar a falsificação e distribuição ilegal de conteúdos digitais (Duarte et al., 2011; Pamboukian, 2007).

A marca d'água é uma informação adicional que uma imagem carregará garantindo sua integridade e 
os direitos autorais sobre a mesma. Sua aplicação varia de acordo com o objetivo que se deseja. Independente disso, uma boa marca d'água deve ser invisível ao sistema visual humano (HVS) e interferir o mínimo possível no conteúdo digital da imagem hospedeira (Pamboukian, 2007).

A manipulação da marca d'água é dividida em três fases, inserção, extração e verificação. Atualmente, existem várias técnicas voltadas para estes objetivos, havendo a constante melhoria dos métodos existentes ou a proposição de novos (Duarte et al., 2011; Pamboukian, 2007).

Este trabalho apresenta uma proposta para inserção de marca d'água em imagens digitais, buscando robustez da marca d'água e a proteção autoral da imagem hospedeira. Para isto, o texto está organizado da seguinte forma; a seção II apresenta de forma resumida o processo de inserção e extração da marca d'água, a seção III apresenta a transformada wavelet discreta bidimensional, a seção IV, o método proposto, a seção $\mathrm{V}$, os resultados de aplicações do método proposto e, finalmente, na seção VI estão as conclusões sobre o trabalho.

\section{Inserção e Extração de Marca D’ Água}

A inserção de marca d'água, inicialmente, pode ser vista como a simples tarefa de adicionar ou sobrepor uma imagem a outra. Porém, por questões de integridade, essa operação não satisfaz alguns objetivos do uso de marca d'água (Pamboukian, 2007). Não há requisitos para a escolha do tipo de marca d'água a ser utilizada e sim de como ela deve se comportar quando inserida numa imagem.

Ao inserir uma marca d'água, independente da sua natureza, o simples ato de adicionar informações pode modificar totalmente o conteúdo digital da imagem hospedeira, tanto com relação à quantidade de memória para seu armazenamento, quanto à qualidade visual. Sobrepondo uma imagem à outra, visualmente, se elas possuem a mesma dimensão não é possível diferenciá-las como mostra a figura 1(b).

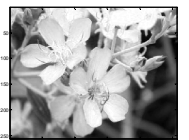

(a)

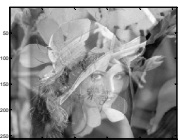

(b)
Figura 1. (a) Imagem $(256 \times 256)$ considerada a marca d'água; (b) Imagem artística autenticada pela imagem considerada como sendo a marca d'água.
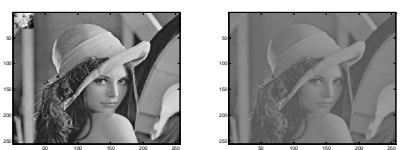

Figura 2. (a) Imagem artística $(256 \times 256)$ autenticada por uma marca d'água visível $(32 \times 32)$; (b) Imagem artística $(256 \times 256)$ autenticada por uma marca d'água pseudoaleatória $(n=256)$

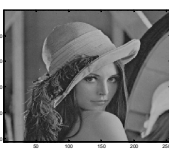

(a)

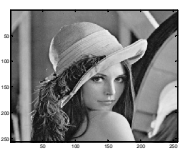

(b)
Figura 3. (a) Imagem artística $(256 \times 256)$ autenticada por marca d'água aleatória $(\mathrm{n}=256)$; (b) Imagem artística $(256 \times 256)$ autenticada por marca d'água binária $(32 \times 32)$.

Esse problema já não aparece quando as imagens têm dimensões diferentes, já que é fácil detectar a marca d'água, por ser menor. Mas, isto só ocorre quando a marca d'água é visível. Quando ela é invisível não é possível tal detecção. Nesse sentido, algumas técnicas recorrem à aplicação da função de sensibilidade baseada no HVS, pois a visão humana é menos sensível a cores do que à luminosidade, onde o brilho é mais intenso ou muito baixo (Lee et al., 1994).

Seria fácil pensar que, aumentando do brilho da marca d'água ela se tornará menos visível. Porém, isso acarretará problemas de espaço computacional, já que quanto mais brilho uma imagem possui mais espaço para armazenamento ela necessita, como ilustra a figura 4 , para uma imagem de $32 \times 32$ pixels.

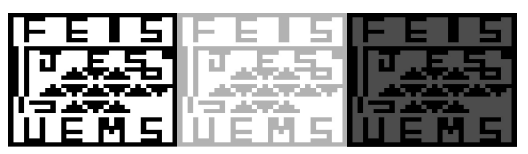

(a)

(b)

(c)

Figura 4.(a) Marca d'água $(32 \times 32)$ normal (29 KB); (b) Marca d'água $(32 \times 32)$ com brilho intenso $(23 \mathrm{~KB})$; (c) Marca d'água (32x32) com ausência de brilho (22 KB).

Uma forma de contornar o problema é recorrer à função de sensibilidade de contraste que reforça o efeito de transparência da marca d'água (Duarte et al, 2011). Na inserção, por não ser baseada em sobreposição de imagens, tanto a imagem hospedeira como a marca d'água passa por transformações decorrentes do processamento atribuído ao uso ferramentas matemáticas que facilitam a inserção da marca d'água sem agredir a imagem hospedeira. Dentre as ferramentas disponíveis na área de processamento de sinais esta a transformada wavelet (TW) (Silva et al., 2007; Stollnitz et al., 1996).

Os métodos analisados buscam garantir a integridade da marca d'água inserida para uma futura verificação de integridade da imagem hospedeira ou simplesmente da própria marca d'água. Além disso, os mesmos garantem a qualidade visual da imagem hospedeira, inserindo marcas d'água robustas.

$\mathrm{Na}$ extração da marca d'água é feito o processo inverso da inserção o que leva a obter no final da extração, mesmo após a imagem marcada sofrer algum tipo de ataque, a marca d'água inserida perfeita ou quase perfeita. Essa comparação é feita calculando a correlação normalizada entre as marcas d'água inserida e a extraída. (Duarte et al., 2011; Pamboukian, 2007). 


\section{Transformada Wavelet Discreta Bidimensio- nal}

Matematicamente, uma imagem digital pode ser representada por uma matriz. Onde cada elemento da matriz representa a intensidade de luminosidade dos pixels da imagem no espaço de cores. Essa característica matemática comum entre imagens digitais e matrizes facilita o processamento das mesmas (Silva, 2008; Stollnitz et al., 1996). Tanto a imagem hospedeira quanto a marca d'água são convertidas do domínio do tempo para o domínio da frequência através da transformada wavelet. Por se tratar de sinais bidimensionais é aplicada a Transformada Wavelet Discreta Bidimensional e se resume em duas formas distintas de decomposição da matriz que representa a imagem. A primeira é chamada de decomposição padrão na qual primeiro se aplica a DWT em todas as linhas da matriz para depois aplicá-la em suas colunas. A segunda é a não padrão que alterna as aplicações da DWT nas linhas e nas colunas da matriz que representa a imagem.

A decomposição não padrão é mais vantajosa quando se deseja fazer mudanças na matriz, pois ela realiza uma análise de multirresolução na imagem, de acordo com suas faixas de frequências (Stollnitz et al., 1996). Neste trabalho será usada a decomposição não padrão, que doravante será chamada de DWTB, por simplicidade de notação. A figura 5 ilustra o processo de decomposição de uma imagem pela DWTB.

Figura 5. Decomposição de uma imagem pela DWTB.

Pensando em conteúdo de frequência, a DWTB decompõe a imagem nas direções horizontal e vertical, resultando em uma sub-banda de baixa frequência (Low frequency Low frequency - LL) e três subbandas de alta frequência (High frequency Low frequency - HL, Low frequency High frequency - LH e High frequency High frequency - HH). Este mesmo processo é repetido na sub-banda LL para gerar o próximo nível de decomposição. A decomposição pode ser repetida nas sub-bandas $\mathrm{LL}_{\mathrm{k}}$ até $\mathrm{o}$ nível $k=\log _{2}(N)$, sendo $N$ a dimensão da imagem. Neste caso uma imagem quadrada de $N x N$ pixels. Numa imagem decomposta pela DWT até o nível $k$, os coeficientes de detalhes horizontais estão em $H L_{k}$, os verticais em $L H_{k}$, os detalhes da diagonal estão em $H H_{k}$ e $L L_{k}$ é uma aproximação da imagem neste nível.

$\mathrm{Na}$ inserção da marca d'água tanto a marca d'água quanto a imagem hospedeira se encontram no domínio da freqüência. Desde modo, escolhe-se uma das sub-bandas de frequência para a inserção. As sub-bandas $L L_{k}$ e $H H_{k}$ podem se descartadas, pois as primeiras contêm os coeficientes de maiores magnitudes da imagem transformada e as segundas, no caso de um ataque de compressão, serão facilmente descartadas. Na escolha de qual sub-banda deve ser inserida a marca d'água deve-se levar em conta tanto a qualidade visual da imagem hospedeira quanto a robustez da marca d'água não a deixando suscetível a ataques.

Mesmo assim, alguns métodos fazem a inserção da marca d'água em $L L_{k}$, por se tratar de uma aproximação da imagem original (Duarte et al., 2011).

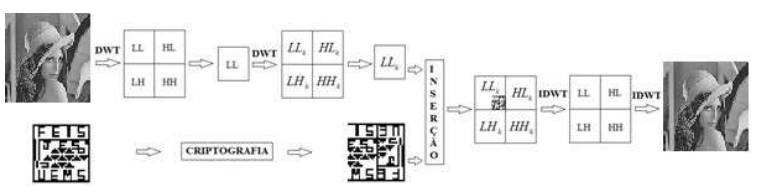

Figura 6: Inserção de marca d'água numa imagem no domínio wavelet.

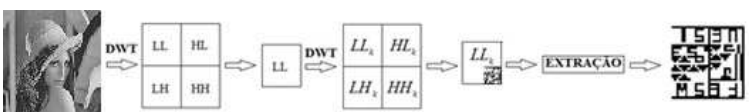

Figura 7. Extração de marca d'água numa imagem no domínio wavelet

\section{Método Proposto}

O método proposto neste trabalho usa a DWTB para decompor a imagem hospedeira e a marca d'água antes da inserção. A imagem e a marca d'água são preparadas de forma independente antes de inserção. Este método é classificado como semicego, pois necessita apenas da marca d'água original no processo de verificação (Duarte et al, 2011).

A imagem é decomposta em um nível de resolução pela DWTB, a sub-banda $H L_{l}$ é escolhida para a inserção da marca d'água. Para isto ela é decomposta mais uma vez pela DWTB, obtendo uma segunda sub-banda de coeficientes de detalhes da imagem $H L_{2}$, onde a marca d'água será inserida. Ao aplicar a DWT duas vezes na mesma sub-banda, estamos tomando um ramo da árvore de decomposição da WPT (Wavelet Packet transform). A sub-banda escolhida para a inserção é a mesma usada por Hajjara et al. em (Hajjara et al., 2009). Porém, neste trabalho, esta escolha foi feita após vários testes em outras subbandas e com outros níveis de resolução da DWTB, onde se pôde verificar que os melhores resultados são obtidos na sub-banda $H L_{2}$ de $H L_{1}$ e as formas de inserção e extração e criptografia da marca d'água são totalmente diferentes das usadas em (Hajjara et al., 2009).

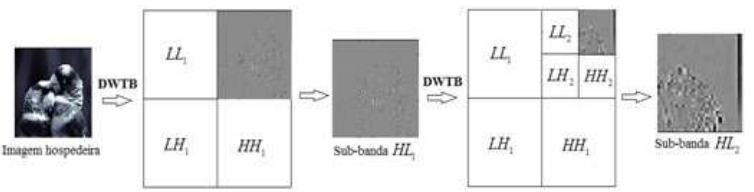

Figura 8: Preparação da região hospedeira da marca d'água. 
A criptografia da marca d'água é feita usando a técnica Arnold's Cat Map (ACM) que é uma importante técnica de criptografia usada para melhorar a segurança de marcas d'água digitais (Huang et al., 2010).

Esta técnica é periódica de período $\mathrm{T}$, ou seja, após $\mathrm{T}$ processos sucessivos de transformação a imagem original é recuperada.

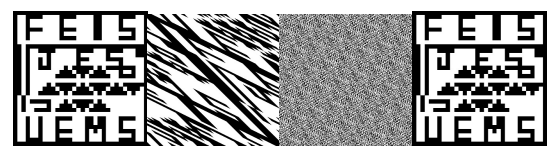

Figura 9. Representação da resultante do algoritmo Arnold's Cat Map aplicado na marca d'água $(32 \times 32)$

A técnica ACM é definida na equação (1).

$\left[\begin{array}{l}x^{\prime} \\ y^{\prime}\end{array}\right]=\left[\begin{array}{ll}1 & 1 \\ 1 & 2\end{array}\right] \cdot\left[\begin{array}{l}x \\ y\end{array}\right] \bmod N, \quad(x, y \in\{0,1,2, \ldots, N-1\}$

sendo $x$ e $y$ as coordenadas do pixel na marca d'água, $x^{\prime}$ e $y^{\prime}$ as novas coordenadas após o processo de transformação, $N$ o tamanho da marca d'água e a função $(d \bmod q)$ retorna o resto da divisão de $d$ por $q$.

Ao ser preparada para a inserção, a marca d'água de dimensão $m \times m$ é decomposta uma vez pela DWTB. Depois, a marca transformada é dividida em 4 blocos de dimensões $(m / 2) \times(m / 2)$. Em cada bloco é aplicado ao algoritmo ACM $\lceil\boldsymbol{T} / 2\rceil$ vezes, sendo $T$ o período ACM de cada bloco e $\lceil\boldsymbol{x}\rceil$ retorna o menor inteiro maior que $x$. Após passar pelo algoritmo ACM, ainda é feita a troca dos elementos que estão em posições simétricas em relação à diagonal secundária em cada bloco, buscando dar mais segurança ao processo.

A inserção da marca d'água é feita por sobreposição, os 4 blocos são inseridos aleatoriamente nos cantos da sub-banda $H L_{2}$ da matriz hospedeira. Ou seja, os coeficientes wavelet da subbanda $H_{2}$ são substituídos pelos coeficientes wavelet da marca d' água. E, finalmente, a imagem marcada é obtida aplicando a DWTB inversa uma vez em $H L_{2}$ e mais uma vez em toda a imagem que foi transformada inicialmente.

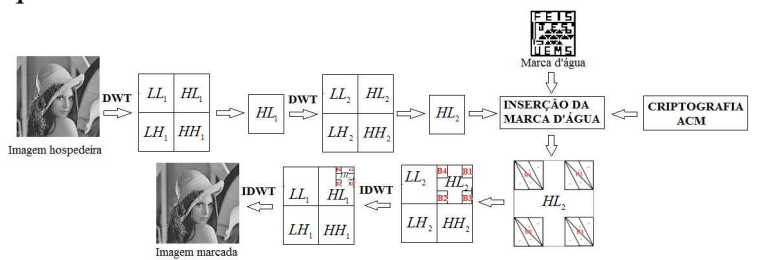

Figura 10. Finalização da etapa de inserção da marca d'água

Na extração da marca d'água é feito o processo inverso. Primeiro a imagem marcada é decomposta em um nível pela DWTB, depois a sub-banda $H L_{l}$ é decomposta também em um nível, em seguida os quatro cantos de $H L_{2}$ são extraídos com as mesmas dimensões dos blocos da marca d'água. Cada bloco tem seus elementos simétricos em relação à diagonal secundária trocados de posição e, em seguida, o algo- ritmo ACM é aplicado $\lfloor T / 2\rfloor$ vezes, sendo que $\lfloor\boldsymbol{x}\rfloor$ retorna o maior inteiro menor que $x$. Finalmente, são feitas as combinações possíveis dos blocos para a recuperação da marca d'água no domínio wavelet. A combinação ideal é aquela que, no caso de ausência de ataque, obtiver correlação perfeita (igual a 1,0) com a marca d'água inserida, também no domínio wavelet. Após encontrar a combinação ideal, a marca d'água recuperada é obtida através de uma aplicação da DWTB inversa nesta combinação.

A inserção e a extração da marca d'água são feitas de forma bem simples, porém o processo é seguro, pois a criptografia da marca d'água passa pela aplicação ACM, pela troca dos elementos em relação à diagonal secundária e pela distribuição aleatória dos blocos da marca nos cantos da sub-banda $H L_{2}$. Assim, alguém que obtiver a imagem marcada de forma ilícita, dificilmente conseguirá extrair a marca d'água da mesma, pois não terá informações como dimensão da marca, período ACM da mesma e ordem de alocação dos blocos na sub-banda escolhida para inserção.

\section{Testes e Resultados}

Testes numéricos com o método proposto foram realizados usando como imagem hospedeira imagem em escala de cinzas de $2048 \times 2048$ e como marcas d'água duas imagens binárias de $32 \times 32$ pixels e $16 \times 16$ pixels, todas as imagens usadas são de propriedade dos autores do trabalho, tanto a imagem hospedeira quanto as marcas d'água. Os algoritmos de inserção e extração da marca d'água e da DWTB direta e inversa foram implementados usando o Software MATLAB ${ }^{\circledR}$. A função wavelet usada na DWTB foi a wavelet 6 de Daubechies (Db6) (Daubechies, 1992), escolhida após vários testes. Nas figuras 11 , 12 e 13 são apresentadas a imagem original, as marcas d'água e a imagem marcada, respectivamente. A imagem usada como imagem hospedeira é de propriedade dos autores deste trabalho.

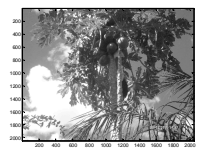

Figura 11. Imagem original.

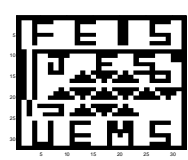

(a)

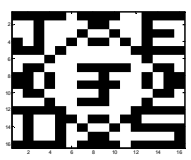

(b)
Figura 12. (a) Marca d'água $32 \times 32$; (b) Marca d'água $16 \times 16$

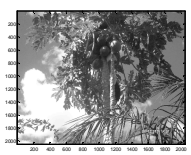

(a)

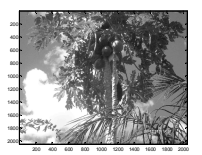

(b)
Figura 13. Imagem marcada com Marca d'água 32×32 e Imagem marcada com Marca d'água $16 \times 16$. 
Foram aplicados três tipos de ataque à imagem marcada para posterior extração da marca d'água, a compressão com perdas, (Silva, 2008), com três taxas de compressão (TC) $30 \%, 40 \%$ e $50 \%$ e a contaminação da imagem com $40 \%$ de ruído gaussiano branco e posterior compressão com as mesmas taxas usadas no ataque de compressão e a compressão JPEG. Os resultados desses experimentos são mostrados a seguir.

\subsection{Experimento 1: Compressão com perdas 5.1.1 Marca d'água $32 \times 32$}

Na figura 14 são apresentadas as marcas d'água extraídas após o ataque de compressão com marca d'água $32 \times 32$ pixels na imagem hospedeira.

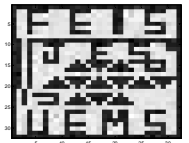

(a)

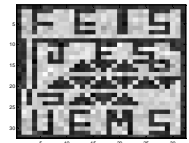

(b)

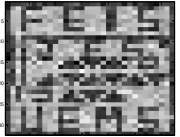

(c)
Figura 14. (a) Marca d'água extraída após ataque de compressão com TC de 30\%; (b) Marca d'água extraída após ataque de compressão com TC de 40\%; (c) Marca d'água extraída após ataque de compressão com TC de 50\%.

\subsubsection{Marca d'água $16 \times 16$}

Na figura 15 são apresentadas as marcas d'água extraídas após o ataque de compressão com marca d'água $16 \times 16$ pixels na imagem hospedeira.

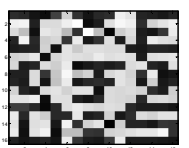

(a)

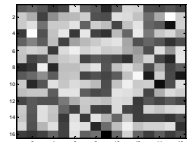

(b)

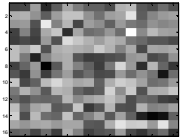

(c)
Figura 16. (a) Marca d'água extraída após ataque de compressão com TC de 30\%;(b) Marca d'água extraída após ataque de compressão com TC de $40 \%$. (c) Marca d'água extraída após ataque de compressão com TC de 50\%.

\subsection{Experimento 2: Ataque ruidoso}

\subsubsection{Marca d'água $32 \times 32$.}

Na figura 17 são apresentadas as marcas d'água extraídas após o ataque de compressão com marca d'água $32 \times 32$ pixels na imagem hospedeira.

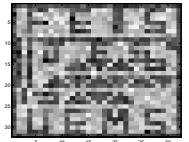

(a)

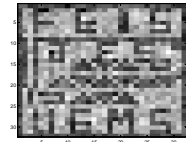

(b)

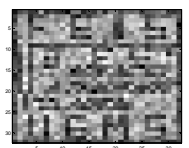

(c)
Figura 17. (a) Marca d'água extraída após ataque ruidoso seguido de compressão com TC de 30\%; (b) Marca d'água extraída após ataque ruidoso seguido de compressão com TC de $40 \%$; (c) Marca d'água extraída após ataque ruidoso seguido de compressão com $\mathrm{TC}$ de $50 \%$.

\subsubsection{Marca d'água $16 \times 16$.}

$\mathrm{Na}$ figura 18 apresentam-se as marcas extraídas após o ataque de adição de $40 \%$ de ruído gaussiano branco à imagem marcada e posterior compressão com marca d'água $16 \times 16$ pixels na imagem de hospedeira.

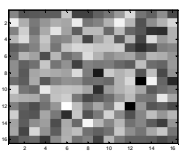

(a)

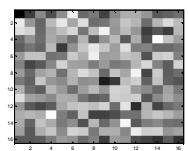

(b)

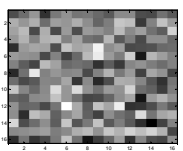

(c)
Figura 18. (a) Marca d'água extraída após ataque ruidoso seguido de compressão com TC de 30\%; (b) Marca d'água extraída após ataque ruidoso seguido de compressão com TC de 40\%; (c) Marca d'água extraída após ataque ruidoso seguido de compressão com TC de $50 \%$

\subsection{Experimento 3 : Ataque JPEG}

a) Marca d'água $32 \times 32$

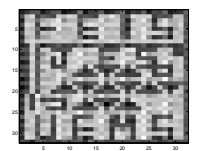

(a)

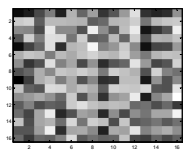

(b)
Figura 19. Marcas d'água extraídas após ataque JPEG na imagem hospedeira: (a) $32 \times 32$ e (b) $16 \times 16$

Duas métricas são usadas no processo, a PSNR (Peak Signal-to-Noise Ratio) que mede o nível de distorção de uma imagem quando a mesma passa por alguma transformação e a correlação normalizada (NC) usada para calcular a similaridade entre a marca d'água inserida e a extraída após os ataques (Huang et al., 2010) A PSNR será sempre calculada comparando a imagem original e a imagem marcada após o ataque. Quanto maior a PSNR, que é medida em decibéis $(\mathrm{dB})$, menor é o nível de distorção na imagem. Quanto mais próxima de 1,0 estiver a NC, maior é a semelhança entre a marca d'água inserida e a extraída. A imagem marcada apresentou PSNR de 38,78 dB. As equações (2) e (3) apresentam, respectivamente, as formas de se calcular a PSNR e a correlação normalizada.

$$
P S N R=10 \log _{10} \frac{d^{2}}{M S E}
$$

Sendo $d$ a dimensão da imagem.

$$
M S E=\sum_{i=1}^{A} \sum_{j=1}^{L}\left(I_{i j}-I_{i j}^{\prime}\right) / d
$$

Sendo $I$ a imagem original, $I$ ' a imagem modificada, $A$ a altura e $L$ a largura das imagens.

$$
N C\left(W, W^{\prime}\right)=\sum_{m=1}^{N_{w}}\left(w_{m} \cdot w_{m}^{\prime}\right) / \sqrt{\left(\sum_{m=1}^{N_{w}} w_{m}^{2} \sum_{m=1}^{N_{w}} w_{m}^{\prime 2}\right) / N_{w}}
$$

Na equação (4), W é a marca d'água inserida e W' a extraída e $N w$, o número de pixels da marca d'água.

As tabelas 1, 2 e 3 apresentam os valores de PSNR para as imagens e os valores de NC entre as marcas d'águas após os respectivos ataques de compressão, adição de ruído seguido de compressão e compressão JPEG, respectivamente. 
Tabela 1. PSNR e NC após ataque de compressão

\begin{tabular}{|c|c|c|c|c|c|c|}
\hline \multirow{2}{*}{$\begin{array}{c}\text { Marca } \\
\text { d'água }\end{array}$} & \multicolumn{3}{|c|}{ PSNR (dB) } & \multicolumn{3}{c|}{ NC } \\
\cline { 2 - 7 } & $30 \%$ & $40 \%$ & $50 \%$ & $30 \%$ & $40 \%$ & $50 \%$ \\
\hline $32 \times 32$ & 37,512 & 35,297 & 32,227 & 0,994 & 0,978 & 0,930 \\
\hline $16 \times 16$ & 39,623 & 36,428 & 32,751 & 0,995 & 0,9712 & 0,885 \\
\hline
\end{tabular}

Tabela 2. PSNR e NC após ataque ruidoso seguido de compressão

\begin{tabular}{|c|c|c|c|c|c|c|}
\hline \multirow{2}{*}{$\begin{array}{c}\text { Marca } \\
\text { d'água }\end{array}$} & \multicolumn{3}{|c|}{ PSNR $(\mathrm{dB})$} & \multicolumn{3}{c|}{ NC } \\
\cline { 2 - 7 } & $30 \%$ & $40 \%$ & $50 \%$ & $30 \%$ & $40 \%$ & $50 \%$ \\
\hline $32 \times 32$ & 31,912 & 31,463 & 30,233 & 0,917 & 0,901 & 0,831 \\
\hline $16 \times 16$ & 31,912 & 31,464 & 30,234 & 0,830 & 0,830 & 0,759 \\
\hline
\end{tabular}

Tabela 3. PSNR e NC após ataque JPEG

\begin{tabular}{|c|c|c|}
\hline $\begin{array}{c}\text { Marca } \\
\text { d'água }\end{array}$ & PSNR $(\mathrm{dB})$ & $\mathrm{NC}$ \\
\hline $32 \times 32$ & 38,7847 & 0,9597 \\
\hline $16 \times 16$ & 41,7768 & 0,9158 \\
\hline
\end{tabular}

Os resultados apresentados nas Tabelas 1, 2 e 3, corroborados pelas figuras $14,15,16,17,18$ e 19, mostram a eficiência e robustez do método proposto, pois as marcas extraídas são recuperadas com valores de NC sempre próximos de 1,0 e, visualmente, é possível identificar a marca d'água, mesmo após a contaminação da imagem marcada por ruído branco seguida de compressão com $50 \%$ de TC.

Os resultados obtidos neste trabalho são melhores que os apresentados em (Huang et al., 2010), pois o máximo de TC que eles usaram foi $32,74 \%$ obtendo NC média igual a 0,89 e, no caso de ataque com ruído gaussiano, usando uma porcentagem menor que nesse trabalho, eles obtiveram NC média de 0,84 . Os resultados obtidos em (Hajjara et al., 2009) são praticamente iguais aos desse trabalho, porém adicionando apenas $20 \%$ de ruído e com TCs também inferiores. Em (Hajjara et al., 2009) é aplicado um fator de ganho na inserção da marca d'água. Sem esse fator de ganho seus resultados são inferiores aos aqui obtidos.

\section{Conclusão}

Neste trabalho foi apresentada uma nova abordagem para inserção e extração de marca d'água em imagens digitais. Por meio da transformada wavelet discreta bidimensional a imagem hospedeira e a marca d'água são preparadas para posterior inserção. Para criptografar a marca d'água, a mesma é dividida em 4 blocos e, em cada bloco, aplica-se o algoritmo ACM e realiza-se a troca das posições dos elementos simétricos em relação à diagonal secundária. Por fim, faz-se a distribuição aleatória desses blocos na sub-banda de frequências da matriz hospedeira, escolhida para a inserção. Os resultados obtidos nos testes numéricos mostraram que a metodologia apresentada é robusta aos ataques de compressão com perdas, adição de ruído à imagem marcada e compressão JPEG, apresentando ótimos valores de correlação com consideráveis taxas de compressão e nível de ruído.

\section{Referências Bibliográficas}

Daubechies, I., "Ten Lectures on Wavelets", SIAM, Philadelphia, 1992. DOI: 10.1137/1.9781611970104

Duarte, M. A. Q., Silva, J. F., Villarreal, F. "Análise de Métodos de Inserção e Extração de Marca D’água no Domínio Wavelet”, 10a Conferencia Brasileira de Dinâmica, Controle e Aplicações DINCON 2011, Águas de Lindóia - SP, 2011.

Hajjara, S., Abdallah, M., Hudaib, A., "Digital Image Watermarking Using Localized Biorthogonal Wavelets", European Journal of Scientific Research, vol. 26, n. 4, pp. 594-608, (2009).

Huang, W. T., Tan, S. Y., Chang, Y. J., Chen, C. H., "A Robust Watermarking for Copyright Protection Using Discrete Wavelet Transform", WSEAS Transactions on Computers, vol. 9, n. 5, pp. 485-495, (2010).

Lee, I., Ki, I., Kim, J., Kim, Y., Park S., G. and Park, K. T., "Wavelet transform image coding using human visual system," Proc. IEEE Circuits and Systems, Taiwan, pp. 619-623, 1994.

Pamboukian, S. V. D., "Marcas D'água de Autenticação para Imagens Binárias: Marcas Reversíveis e Marcas para o Padrão JBIG2 2007”, Tese de Doutorado, Escola Politécnica da Universidade de São Paulo, 2007.

Silva, J.F., Duarte, M. A. Q., Villarreal F., Soares, W. C., "Processamento Digital de Imagens e a Transformada Wavelet", 6th Brazilian Conference on Dynamics, Control and Their Applications, São José do Rio Preto - SP, 2007.

Silva, J. F., "Sistema de Armazenamento de Imagens Comprimidas através da Transformada Wavelet”, Dissertação de Mestrado, PPGEE-UNESP, Ilha Solteira, 2008.

Stollnitz, E. J., De Rose, T. D., Salesin, D. H., "Wavelets for Computer Graphics Theory and Applications", Morgan Kaufmann Publishers, Inc. San Francisco, California, 1996.

Wysocki, T. A., Honary, B., Wysocki, B. J. (editores), "Signal Processing For Telecommunica-tions and Multimedia", Springer, Boston, 2005. DOI: 10.1007/b99846 